\title{
ASSOCIATION OF DIABETES IN PREGNANCY WITH THYROID DYSFUNCTION
} AND AUTOIMMUNITY

\section{Dr. Ekta Kanojia*}

\section{Dr. Suman Lata} Mendiratta

\section{Dr. Vineeta Sarbhai}

Post Graduate Student, Department Of Obstetrics And Gynaecology, Kasturba Hospital, Daryaganj, New Delhi-1 10002. *Corresponding Author Professor And Head, Department Of Obstetrics And Gynaecology, Kasturba Hoapital, Daryaganj, New Delhi-1 10002.

Associate Proffessor, Department Of Obstetrics And Gynaecology, Kasturba Hospital, Daryaganj New Delhi-1 10002.

ABSTRACT PURPOSE: This study was undertaken to find out the proportion of women with diabetes in pregnancy complicated by thyroid dysfunction compared to non-diabetic pregnant women. To find out the association, if any, of thyroid dysfunction and anti-thyroid peroxidase (anti-TPO) antibodies during pregnancy with typel diabetes mellitus, type 2 diabetes mellitus, gestational diabetes mellitus (GDM) and non-diabetic pregnant women. METHODS: A cross-sectional observational study was conducted in a tertiary care teaching hospital in New Delhi, India, for a period of one year. 100 women with diabetes in pregnancy and 100 non-diabetic pregnant women were recruited from the antenatal clinic. The women were evaluated for thyroid dysfunction, thyroid autoimmunity and were managed according to the hospital's protocols. The relevant data were recorded and statistical analysis was done. RESULTS: $24 \%$ of women with diabetes in pregnancy and 8\% of non-diabetic women had hypothyroidism. Subclinical hypothyroidism was most prevalent in women with GDM (15.25\%) and overt hypothyroidism was most prevalent in women with type 1 DM (28.57\%). Mean serum TSH levels were highest in women with type $1 \mathrm{DM}$. Positive anti-TPO antibodies were significantly associated with diabetes in pregnancy compared to non-diabetic women $(p=0.02)$. Amongst women with diabetes in pregnancy, positive anti-TPO antibodies were significantly associated with type 1 DM $(p<0.01)$. CONCLUSIONS: Thyroid disorders are commonly associated with diabetes in pregnancy. The study findings suggest routine screening for thyroid abnormalities in diabetic pregnant women.

KEYWORDS : Type1 Dm, Type2 Dm, GDM, anti-TPO Antibodies, fT4, TSH.

\section{INTRODUCTION}

Pregnancy leads to numerous hormonal and metabolic changes which results in complex effect on carbohydrate homeostasis and thyroid function. The mutual influence of diabetes and thyroid dysfunction on each other can have devastating effects on pregnancy outcome.

Diabetes in pregnancy is classified as Pre-gestational diabetes, which consists of (i) Insulin dependent or Type 1 diabetes mellitus (ii) Insulin independent or Type 2 diabetes mellitus and Gestational Diabetes Mellitus (GDM).

Pre-gestational diabetes as well as Gestational diabetes mellitus can be associated with thyroid dysfunction and autoimmunity. Autoimmune thyroid disease is the most frequent autoimmune disease associated with type l diabetes mellitus. Higher prevalence of thyroid autoimmunity has been found in women who have had previous GDM and it has been speculated that gestational hyperglycaemia may trigger thyroid autoimmunity ${ }^{[1]}$. High titres of anti-TPO in a GDM could potentially further compromise the known foetal and maternal complications associated with GDM. ${ }^{[2]}$

\section{MATERIAL AND METHODS}

This hospital based cross sectional descriptive study was conducted in the Department of Obstetrics and Gynaecology, Kasturba Hospital, New Delhi India from January 2019 to December 2019.

\section{Inclusion criteria}

1. Pregnant women with diabetes attending the antenatal clinic directly or were referred from the diabetic clinic of the hospital.

2. Pregnant women with Gestational Diabetes Mellitus diagnosed by a single step $75 \mathrm{~g}$ oral glucose tolerance test (OGTT), any time after 20 weeks of gestation, as per using American Diabetes Association (ADA), 2015 Criteria ${ }^{[3]}$. GDM was diagnosed if one of the plasma glucose values equals or exceeded- fasting plasma glucose of $92 \mathrm{mg} / \mathrm{dl}$ $(5.1 \mathrm{mmol} / \mathrm{l})$, l-hour plasma glucose of $180 \mathrm{mg} / \mathrm{dl}$ (10.0mmol/1), 2-hour plasma glucose of $153 \mathrm{mg} / \mathrm{dl}$ $(8.5 \mathrm{mmol} / \mathrm{l})$.

Exclusion criteria

1. Pregnancy with gestation period of $>34$ weeks.

2. Multi-fetal pregnancy.

3. Pregnant women who are already in labour.

4. H/o hypertension, heart disease, renal disease or any other chronic medical disorder at the time of enrolment study.

100 pregnant women fulfilling the inclusion and exclusion criterion were taken as cases consisting of 59 women with deranged OGTT, 14 women with type 1 DM and 27 women with type $2 \mathrm{DM}$.

100 Pregnant women with negative OGTT, without any definite history or diagnosis of diabetes mellitus, with no known thyroid dysfunction, not receiving any medication that could influence thyroid function or the immune system were taken as controls.

Estimation of serum FT4 \& TSH was carried out by the electrochemiluminescence technique using available kits in all cases and controls. Sub Clinical Hypothyroidism was defined as a serum TSH level above the trimester specific upper limit with normal FT4 concentration and Overt Hypothyroidism was defined as serum TSH level above the trimester specific upper limit with low Ft4 levels. TSH $>10 \mathrm{mIU} / 1$ irrespective of FT4 levels is overt hypothyroidism.

TABLE NO. 1 LABORATORY REFERENCE VALUES ${ }^{[4]}$ :

\begin{tabular}{|l|l|l|l|}
\hline & $\begin{array}{l}\text { First } \\
\text { Trimester }\end{array}$ & $\begin{array}{l}\text { Second } \\
\text { Trimester }\end{array}$ & $\begin{array}{l}\text { Third } \\
\text { Trimester }\end{array}$ \\
\hline Free T3 pg/dl & $2.53-4.54$ & $2.0-4.73$ & $2.01-4.01$ \\
\hline Free T4 ng/dl & $0.88-1.78$ & $0.91-1.78$ & $0.83-1.73$ \\
\hline TSH mIU/ml & $0.37-3.69$ & $0.54-4.47$ & $0.70-4.64$ \\
\hline
\end{tabular}


Anti-TPO antibodies were estimated in all patients at the time of first antenatal visit. TPO antibody assay was done using indirect ELISA technique, anti-TPO was considered positive if levels were more than $55 \mathrm{IU} / \mathrm{ml}$

Data were collated and analyzed statistically using unpaired t-test and chi-square test.

\section{RESULTS}

TABLE NO.2 CHRACTERSTICS OF DIABETIC PREGNANT WOMEN AND NON-DIABETIC PREGNANT WOMEN

\begin{tabular}{|c|c|c|c|}
\hline & $\begin{array}{c}\text { Diabetic } \\
\text { pregnant women } \\
(\mathbf{n}=100)\end{array}$ & $\begin{array}{c}\text { Non- diabetic } \\
\text { pregnant women } \\
(\mathrm{n}=100)\end{array}$ & $\begin{array}{c}\text { P- } \\
\text { value }\end{array}$ \\
\hline Mean age & $27.45 \pm 5.43$ years & $25.54 \pm 4.21$ years & $<0.01$ \\
\hline Primigravida & $35(35 \%)$ & $36(36 \%)$ & 0.99 \\
\hline Multigravida & $65(65 \%)$ & $64(64 \%)$ & 0.99 \\
\hline $\begin{array}{c}\text { Weight gain }>10 \\
\text { kg }\end{array}$ & $31(31 \%)$ & $12(12 \%)$ & 0.001 \\
\hline $\begin{array}{c}\text { Family h/o } \\
\text { diabetes }\end{array}$ & $21(21 \%)$ & 0 & $<0.00$ \\
\hline $\begin{array}{c}\text { H/o GDM in } \\
\text { previous } \\
\text { pregnancies }\end{array}$ & $4(4 \%)$ & 0 & - \\
\hline $\begin{array}{c}\text { H/o macrosomia } \\
\text { in previous } \\
\text { Pregnancies }\end{array}$ & $8(8 \%)$ & 0 & - \\
\hline $\begin{array}{c}\text { H/o recurrent } \\
\text { abortions }\end{array}$ & $7(7 \%)$ & $1(1 \%)$ & - \\
\hline
\end{tabular}

The mean age was higher in women with diabetes as compared to non-diabetic pregnant women $(p<0.01)$. Most of the women in both cases and controls were multigravida. 31\% of diabetic pregnant women and $12 \%$ of non-diabetic pregnant women had weight gain of more than $10 \mathrm{~kg}$ $(p<0.001)$. Family history of diabetes was more prevalent in diabetic pregnant women $(\mathrm{p}<0.001)$. History of GDM, macrosomia and recurrent abortions in previous pregnancy was more prevalent in diabetic pregnant women.(Table no.2)

\section{TABLE NO. 3 DISTRIBUTION OF THYROID DYSFUNCTION} AND THYROID AUTOIMMUNITY IN STUDY SUBJECTS

\begin{tabular}{|c|c|c|c|}
\hline & $\begin{array}{c}\text { Diabetic } \\
\text { pregnant women } \\
(\mathbf{n}=100)\end{array}$ & $\begin{array}{c}\text { Non-diabetic } \\
\text { pregnant women } \\
(\mathbf{n}=100)\end{array}$ & $\begin{array}{c}\text { P- } \\
\text { value }\end{array}$ \\
\hline Euthyroid & $76(76 \%)$ & $92(92 \%)$ & $<0.01$ \\
\hline $\begin{array}{c}\text { Subclinical } \\
\text { hypothyroidism }\end{array}$ & $24(24 \%)$ & $5(\%)$ & $<0.01$ \\
\hline $\begin{array}{c}\text { Overt } \\
\text { hypothyroidism }\end{array}$ & $10(10 \%)$ & $3(\%)$ & $<0.01$ \\
\hline $\begin{array}{c}\text { Positive anti- } \\
\text { TPO antibodies }\end{array}$ & $16(16 \%)$ & $6(6 \%)$ & 0.02 \\
\hline
\end{tabular}

In our study, $76 \%$ of diabetic pregnant women and $92 \%$ of nondiabetic pregnant women were euthyroid. Subclinical hypothyroidism $(p<0.01)$, overt hypothyroidism $(p<0.01)$ and positive anti-TPO antibodies $(\mathrm{p}=0.02)$ were more prevalent in diabetic pregnant women with a statistically significant association as compared to non-diabetic pregnant women.(Table no.3)

TABLE NO.4 DISTRIBUSTION OF MEAN TSH, THYROID DYSFUNCTION AND AUTOIMMUNITY AMONGST CASES

\begin{tabular}{|c|c|c|c|c|c|}
\hline & $\begin{array}{c}\text { GDM } \\
(\mathbf{n}=59)\end{array}$ & $\begin{array}{c}\text { Type 1 } \\
\text { DM } \\
(\mathbf{n}=14)\end{array}$ & $\begin{array}{c}\text { Type 2 } \\
\text { DM } \\
(\mathbf{n}=27)\end{array}$ & $\begin{array}{c}\text { Non- } \\
\text { diabetic } \\
(\mathbf{n}=100)\end{array}$ & $\begin{array}{c}\text { P- } \\
\text { value }\end{array}$ \\
\hline $\begin{array}{c}\text { Mean TSH } \\
\text { (mIU/L) }\end{array}$ & $\begin{array}{c}3.03 \pm 2 . \\
26\end{array}$ & $\begin{array}{c}4.88 \pm 4 . \\
65\end{array}$ & $\begin{array}{c}2.44 \pm 1 . \\
79\end{array}$ & $\begin{array}{c}2.31 \pm 1 . \\
40\end{array}$ & $<0.01$ \\
\hline Euthyroid & 45 & 8 & 23 & 92 & $<0.01$ \\
& $(76.28 \%)$ & $(57.14 \%)$ & $(85.19 \%)$ & $(92 \%)$ & \\
\hline $\begin{array}{c}\text { Subclinical } \\
\text { hypothyroidism }\end{array}$ & $\begin{array}{c}9(15.25 \\
\%)\end{array}$ & $\begin{array}{c}2(14.29 \\
\%)\end{array}$ & $\begin{array}{c}3(11.11 \\
\%)\end{array}$ & $5(5 \%)$ & $<0.01$ \\
\hline
\end{tabular}

\begin{tabular}{|c|c|c|c|c|c|}
\hline $\begin{array}{c}\text { Overt } \\
\text { hypothyroidism }\end{array}$ & $5(8.47 \%)$ & $\begin{array}{c}4(28.57 \\
\%)\end{array}$ & $1(3.70 \%)$ & $3(3 \%)$ & $<0.01$ \\
\hline $\begin{array}{c}\text { Positive anti- } \\
\text { TPO antibodies }\end{array}$ & $\begin{array}{c}9(15.25 \\
\%)\end{array}$ & $\begin{array}{c}5(35.71 \\
\%)\end{array}$ & $2(7.41 \%)$ & $6(6 \%)$ & $<0.01$ \\
\hline
\end{tabular}

In our study, women with Type 1 DM had higher mean TSH values. $76.28 \%, 57.14 \%, 85.19 \%$ were euthyroid in GDM, TypelDM and Type2 DM groups respectively as compared to $92 \%$ in controls group. Subclinical hypothyroidism was seen in $15.25 \%$ of GDM group, $14.29 \%$ in Type 1 DM group, $11.11 \%$ in Type $2 \mathrm{DM}$ group as compared to $5 \%$ in controls group. Overt hypothyroidism was seen in $18.47 \%$ of GDM group, $28.57 \%$ in Type $1 \mathrm{DM}$ group, 3.70\% in Type $2 \mathrm{DM}$ group as compared to $3 \%$ in controls group. The difference in thyroid dysfunction was found to be statistically significant $(\mathrm{p}<0.01)$. Subclinical thyroid dysfunction was more commonly seen in GDM group while overt hypothyroidism was most commonly seen in Typel DM group. 15.25\% women in GDM group, $35.71 \%$ of women in type $1 \mathrm{DM}$ group and $7.41 \%$ of women in type $2 \mathrm{DM}$ group were positive for anti-TPO antibodies as compared to $6 \%$ of in controls group. The difference was statistically significant $(p<0.01)$, implying that as compared to the controls group, women with GDM, typel DM and type2 DM were more likely to have positive anti-TPO antibodies. Amongst the cases positive anti-TPO antibody was more commonly seen in women with typel DM.(Table n0.4)

\section{DISCUSSION}

In our study $14 \%$ of cases and $5 \%$ of controls reported subclinical hypothyroidism while $10 \%$ of cases and $3 \%$ of controls reported overt hypothyroidism. Hypothyroidism was more prevalent in women with diabetes than in healthy controls and the difference was statistically significant $(p<0.01)$ Overt hypothyroidism was more prevalent in women with Typel DM as compared to women with GDM, Type 2 DM and controls group, the difference found was statistically significant $(p<0.01)$. Subclinical hypothyroidism was more prevalent amongst women with gestational diabetes mellitus (15.25\%) compared to women with Typel DM, Type 2 DM and controls. The difference was statistically significant $(p<0.01)$

Shahbazian $\mathrm{H}$ et al, 2013 ${ }^{[5]}$ and N.Maleki and Z.Tavosi, 2014 ${ }^{[6]}$ found in their study that thyroid dysfunction was more prevalent in women with GDM and pre-gestational diabetes compared to healthy controls. P Robert J Gallas et al, 2002 ${ }^{[7]}$ found that the prevalence of thyroid dysfunction during pregnancy was 3-fold higher in women with Type 1 diabetes mellitus than the general Dutch population. None of the patients in our study developed sub clinical or clinical hyperthyroidism, similar to results of VelkoskaNakova V et al, $2010^{[8]}$.

In our study mean TSH levels were significantly higher in women with Typel DM $(\mathrm{P}<0.01)$. These women also have highest prevalence of anti TPO antibodies.

VelkoskaNakova V et al, $2010{ }^{[8]}$ found in their study that mean TSH levels were significantly higher in women with positive anti-TPO antibodies.

In our study anti-TPO antibodies were significantly associated with women who had diabetes in pregnancy $(p=0.02)$

Amongst the cases, positive anti-TPO antibodies were more prevalent in women with Typel diabetes mellitus (35.71\%) and it was seen that it is significantly associated with Type 1 diabetes mellitus $(p<0.01)$ as compared to GDM $(15.25 \%)$, Type 2 DM (7.41\%) and non-diabetic controls (6\%)

VelkoskaNakova V et al, $2010^{[8]}$ and Vestgaard $\mathrm{M}$ et al, 2008 ${ }^{[9]}$ found in their study that anti-TPO antibodies were more prevalent in pregnant women with Typel DM compared to healthy pregnant women.. Hiralal Konar et al, $2017^{[10]}$ found 
in his study that anti-TPO antibodies were present in $11.54 \%$ women with GDM and $25 \%$ of women with pre-gestational DM.

\section{CONCLUSION}

There is an increased prevalence of thyroid abnormalities with diabetes which may lead to increased risk of maternal and fetal complications hence routine screening for thyroid abnormalities is recommended in patients with diabetes in pregnancy.

\section{ETHICAL APPROVAL AND CONSENT TO PARTICIPATE}

The study was approved by the institutional ethical committee and all the procedures involving human participation were in accordance with the ethical standards of the institution.

\section{REFERENCES}

1. Elrick, H., Hlad, C. And Arai Y, 1961. Influence Of Thyroid Function On Carbohydrate Metabolism And A New Method For Assessing Response To Insulin. The Journal Of Clinical Endocrinology \& Metabolism, 21 (4) 387-400.

2. Agarwal, M., Dhatt, G., Punnose, J., Bishawi, B., \& Zayed, R. (2006). Thyroid function abnormalities and antithyroid antibody prevalence in pregnant women at high risk for gestational diabetes mellitus. Gynecological Endocrinology, 22(5), 261-266.

3. American Diabetes Association. Diabetes management guidelines. Diabetes care. 2015:38(Suppl 1):S1-S93.

4. Rajput, R., Singh, B., Goel, V., Verma, A., Seth, S., \& Nanda, S. (2016). Trimester-specific reference interval for thyroid hormones during pregnancy at a Tertiary Care Hospital in Haryana, India. Indian Journal Of Endocrinology And Metabolism, 20(6), 810

5. Shahbazian, $\mathrm{H}$. Shahbazian, N Rahimi Baniani, M. Yazdanpanah, L \& Latifi, S. (2013). Evaluation of thyroid dysfunction in pregnant women with gestational and pre-gestational diabetes. Pakistan Journal Of Medical Sciences, 29(2).

6. Maleki, N., \& Tavosi, Z. (2014). Evaluation of thyroid dysfunction and autoimmunity in gestational diabetes mellitus and its relationship with postpartum thyroiditis. Diabetic Medicine, 32(2), 206-212.

7. Gallas, P., Stolk, R., Bakker, K., Endert, E., \& Wiersinga, W. (2002). Thyroid dysfunction during pregnancy and in the first postpartum year in women with diabetes mellitus type l. European Journal Of Endocrinology, 443-451.

8. Velkoska Nakova V. Krstevska, B. Dimitrovski, C. h. Simeonova, S., HadziLega, M., \& Serafimoski, V. (2010). Prevalence of thyroid dysfunction and autoimmunity in pregnant women with gestational diabetes and diabetes type 1.Prilozi, 31(2), 51-59.

9. Vestgaard, M., Nielsen, L., Rasmussen, Å., Damm, P. \& Mathiesen, E. (2008). Thyroid peroxidase antibodies in pregnant women with type 1 diabetes: Impact on thyroid function, metabolic control and pregnancy outcome. Acta Obstetricia Et Gynecologica Scandinavica, 87(12), 1336-1342.

10. Konar, H., Sarkar, M., \& Roy, M. (2017). Association of Thyroid Dysfunction and Autoimmunity in Pregnant Women with Diabetes Mellitus. The Journal Of Obstetrics And Gynecology Of India, 68(4), 283-288. 